\title{
O ENSINO DE ARITMÉTICA SEGUNDO PROFESSORES PRIMÁRIOS PARANAENSES NO INÍCIO DO SÉCULO XX
}

\author{
THE TEACHING OF ARITHMETIC FOR PRIMARY TEACHERS \\ PARANÁ AT BEGINNING OF XX CENTURY
}

\section{RESUMO}

O ensino da Aritmética ocupou um lugar importante na história da escola primária do estado do Paraná, em se tratando de um espaço curricular permeado de representações dos seus principais sujeitos. Considerando que são os professores os agentes que utilizam dispositivos para efetivar o processo de ensino e aprendizagem, este estudo tem por objetivo compreender como se efetivou o ensino de Aritmética na escola primária paranaense no início do século XX. A investigação, orientada na perspectiva da história cultural, privilegiou relatórios elaborados por professores em 1905. Estes relatórios, publicados na revista "A Escola" em 1906, eram destinados ao Inspetor Escolar da Capital. Outras fontes consideradas foram os Relatórios de Governo e livros didáticos de Antônio Trajano, adotados pelos professores. Os relatórios apontaram que os professores tinham a preocupação de tornar a aprendizagem de Aritmética um momento prazeroso, relacionando-a com o cotidiano dos alunos. O estudo mostrou que o ensino de Aritmética realizou-se, no início do século XX, por meio do método intuitivo. Valorizando a dimensão "prática" do ensino, o concreto se fazia presente, tanto no que diz respeito aos materiais, quanto nas relações estabelecidas entre os conteúdos aritméticos e a realidade dos alunos.

Palavras chave: Cultura escolar; história da educação matemática; ensino intuitivo; escola primária paranaense.

\section{ABSTRACT}

Teaching Arithmetic occupied an important place in the history of primary school in the state of Paraná, in the case of a curricular space permeated with representations of their main subjects. Whereas teachers are the agents who use devices to effect the process of teaching and learning, this study aims to understand how was accomplished teaching arithmetic in primary school Paraná in the early twentieth century. The research focused on the perspective of cultural history, privileging reports elaborated by teachers in 1905. These reports, published in pedagogical magazine "The School" in 1906, were sent to the School Inspector of Capital. Other sources considered were the reports of Government and textbooks of Antonio Trajan, adopted by teachers. The reports indicated that teachers were concerned to make learning of Arithmetica a pleasant moment , relating it to the daily lives of students. The study showed that the teaching of Arithmetic was held in the early twentieth century, through the intuitive method. Valuing dimension "practice" of teaching, the concrete was present, both

\footnotetext{
${ }^{11}$ Mestranda em Educação no Programa de Pós Graduação em Educação da Pontifícia Universidade Católica do Paraná.

${ }^{12}$ Professora Titular do Programa de Pós Graduação em Educação da Pontifícia Universidade Católica do Paraná.
}

Revista REAMEC, Cuiabá - MT, n.02, dezembro 2014, ISSN: 2318 - 6674

Revista do Programa de Doutorado da Rede Amazônica de Educação em Ciências e Matemática

http://revistareamec.wix.com/revistareamec 


\section{REVISTA REAMEC \\ Revista da Rede Amazônica de Educação \\ em Ciências e Matemática}



with regard to the materials, as the relationships established between the arithmetic content and the reality of the students.

Keywords: Culture school; history of mathematics education; intuitive teaching; Paraná primary school.

\section{Introdução}

A escola possui um papel criativo de modo que para além dos conteúdos prescritos tece a prática educativa mediante o aparato pedagógico que utiliza. De acordo com Julia (2001), a cultura escolar se constitui pelo conjunto de normas prescritas e pelas práticas de apropriação das orientações oficiais. Entre as prescrições e as práticas é necessário considerar o corpo profissional, agentes educativos "que são chamados a obedecer a essas ordens" (JULIA, 2001, p. 10). Confiar as investigações históricas apenas à legislação e aos documentos oficiais é percorrer um caminho que desconsidera os sujeitos e os significados que estes dão ao mundo, já que tais documentos apontam para idealizações dos que se encontram no poder, nem sempre apropriadas no contexto escolar.

Neste sentido, estudar a cultura escolar é considerar as representações e as apropriações dos sujeitos. Segundo Chartier (1990), as representações são "esquemas intelectuais incorporados que criam as figuras graças às quais o presente pode adquirir sentido, o outro tornar-se inteligível e o espaço ser decifrado” (p. 17). Em outras palavras, investigar as representações se trata em pensar a realidade a partir do sentido dado a ela. É a leitura da realidade que se apresenta a partir das fontes. Sendo assim, a escrita desta história, a História Cultural, não se limita apenas à descrição, mas busca o sentido dado à realidade, dirigindo-se as práticas que contraditoriamente dão significado ao mundo.

Entretanto, também é necessário considerar que as representações "embora aspirem à universalidade de um diagnóstico fundado na razão, são sempre determinadas pelos interesses do grupo que as forjam" (CHARTIER, 1990, p. 17). É neste sentido que pensamos a apropriação. Enquanto as representações são estratégias forjadas por grupos dominantes, existem, em contrapartida, as táticas de apropriação. Chartier (1990) afirma que a apropriação "tem por objectivo uma história social das interpretações, remetidas para as suas determinações fundamentais (que são sociais, institucionais, culturais) e inscritas nas práticas específicas que as produzem” (p. 26). Em outras palavras, a investigação voltada para o conceito de apropriação busca estudar como se deu na prática os usos e interpretações de determinado objeto. 


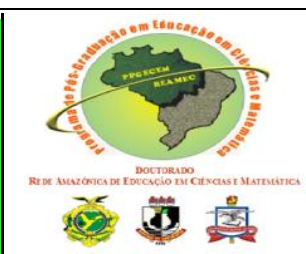

Não existem objectos históricos fora das práticas, móveis, que os constituem, e por isso não há zonas de discurso ou de realidade definidas de uma vez por todas, delimitadas de maneira fixa e detectáveis em cada situação histórica: as coisas não são mais do que as objetivações de práticas determinadas, cujas determinações é necessário trazer a luz do dia. (CHARTIER, 1990, p. 78)

Na história da escola primária do estado do Paraná, o ensino da Aritmética ocupou um lugar importante na cultura escolar, trata-se de um espaço curricular permeado de representações dos seus principais sujeitos, professores e alunos. Sendo assim, considerando que são os professores os agentes que utilizam dispositivos para efetivar o processo de ensino e aprendizagem, temos como objetivo neste artigo compreender, a partir de relatórios escritos por professores, como se efetivou o ensino de Aritmética na escola primária paranaense no início do século XX.

Esta pesquisa, conduzida pela abordagem da história cultural, perpassa um campo interdisciplinar que envolve a Educação, a Matemática e a História. Dentro deste contexto, encontra-se a necessidade de compreender a conjuntura do momento histórico, mantendo-se o diálogo com as dimensões políticas e sociais.

\section{Contexto educacional paranaense}

Ao final do século XIX, o nascimento da República trouxe para a sociedade uma preocupação que ia além da mudança de regime e, neste sentido, a escolarização foi tida como um pilar de sustentação dos novos ideais. Conforme destaca Souza (1998), a educação se tornou uma estratégia de luta e um campo de ação política que estava atrelada à civilização e à cidadania. A escola pública significava um instrumento para a difusão dos valores republicanos e servia para a consolidação de um novo regime político.

Neste sentido, o entusiasmo pela educação levou a um novo modelo de escola primária: os Grupos Escolares. No interior das mudanças, o método intuitivo foi essencial para a nova organização:

É certo que o método intuitivo foi indelével do ensino proposto na história dos grupos escolares, e constantemente utilizada como forma de convencimento para essa moderna pedagogia que se tornava uma realidade. (...) A seriação e a uniformização dos conteúdos sancionados pelo método "lições de coisas" foi responsável por organizar o tempo escolar, distribuindo gradualmente os conteúdos nos quatro anos que compunham o curso primário, o que resultou no uso de livros didáticos, de literatura infantil e cartilhas ajustados ao currículo da escola primária. (BENCOSTTA, 2011, p. 71-72) 


\section{REVISTA REAMEC}

Revista da Rede Amazônica de Educação

em Ciências e Matemática

De escolas sem uniformidade passou-se para um sistema ordenado, com caráter estatal; de um programa que se baseava apenas no "ler-escrever-contar" para uma escola que prezava a educação integral contando com programas enriquecidos e enciclopédicos; de uma escola com acesso restrito para uma escola de acesso obrigatório e universalizado (SOUZA, 1998). O método intuitivo não significou apenas uma nova metodologia para o ensino, mas se contrapôs à organização escolar até então presente, requerendo um novo arranjo escolar.

No contexto paranaense, desde a Proclamação da República, eminentes intelectuais, sobretudo da Escola Normal, já se mobilizavam a fim de "modernizar" o ensino e atender aos novos ideais (PILOTTO, 1954). Porém, é necessário considerar que as mudanças aconteceram de modo lento. O primeiro Grupo Escolar do Paraná, o Grupo Escolar Dr. Xavier da Silva, situado em Curitiba, na Rua Marechal Floriano Peixoto esquina com a Silva Jardim, foi inaugurado em 19 de dezembro de 1903, data em que se comemoravam os 50 anos da criação da Província do Paraná. Desde sua fundação, o Grupo Escolar foi considerado como um grupo modelo (PARANÁ, 1904). Seu primeiro ano de funcionamento foi em 1904, sendo que a uniformização das escolas só ocorreu em 1914 quando Francisco de Macedo, então Diretor da Instrução Pública no Estado do Paraná, propôs uma reforma que reunia as escolas isoladas e criava Grupos e Semi-grupos Escolares. Até 1914 não se encontra vestígios de programas de ensino no Estado, senão Regulamentos que resumidamente elencavam as matérias para o ensino primário e pouca orientação traziam sobre os métodos a serem adotados.

O Regulamento da Instrução Pública do Estado do Paraná de 11 de março de 1901 organiza o ensino primário em $1^{\circ}$ e $2^{\circ}$ grau, sendo que nos dois graus estava prevista a matéria de Aritmética. No $1^{\circ} \mathrm{Grau}$, os ensinamentos se baseavam nas quatro operações e no $2^{\circ}$ Grau era estudada a Aritmética em geral. O referido documento não especifica diretamente o método de ensino a ser adotado, porém, ao elencar os deveres dos professores estabelece que se deva dar ao ensino "o caráter essencialmente prático, tendo sempre em vista as aplicações ás necessidades da vida e a utilidade directa" (Art. 62, inciso 14).

Os Relatórios de Governos ${ }^{13}$ apontam para uma acentuada precariedade do contexto educacional paranaense do início do século XX. Em 1901, Octávio Ferreira do Amaral e

\footnotetext{
${ }^{13}$ Os Relatórios de Governo são documentos importantes, pois retratam a situação geral do Estado em determinado período. Em cada Relatório é reservado um capítulo para tratar da Instrução Pública. Para além das estatísticas, o relator, que na maioria das vezes era o Diretor da Instrução Pública, apontava as carências e avanços do ensino público, reivindicando as melhorias necessárias nas regulamentações e nas condições físicas das escolas.

Revista REAMEC, Cuiabá - MT, n.02, dezembro 2014, ISSN: 2318- 6674

Revista do Programa de Doutorado da Rede Amazônica de Educação em Ciências e Matemática http://revistareamec.wix.com/revistareamec
} 


\section{REVISTA REAMEC \\ Revista da Rede Amazônica de Educação \\ em Ciências e Matemática}

Silva (Secretário de Estado dos Negócios do Interior, Justiça e Instrução Pública) escreve sobre a falta de carteiras e bancos nas escolas paranaenses. Além disso, traz a informação de que há a intenção de uniformizar os livros, informando que a Congregação da Escola Normal havia aprovado a indicação dos livros $1^{\circ}, 2^{\circ}$ e $3^{\circ}$ de leitura Hilário Ribeiro e Gramática Elementar de João Ribeiro. Nenhum referente à Aritmética.

Em 1903, o Diretor Geral da Instrução Pública do Estado do Paraná, Victor Ferreira do Amaral e Silva, expõe em seu relatório que por meio das excursões realizadas no estado, a fim de visitar as escolas, percebeu que o nível da instrução pública estava se elevando. Assim, afirmou que a função da escola não se tratava mais de ensinar apenas a ler, escrever e contar, mas a "missão moderna" era instruir e educar. Cita ainda que visitou o Estado de São Paulo e que lá as condições de ensino eram diferentes, servindo como uma organização modelo. Pelas palavras do Diretor, cada escola no Paraná tinha uma maneira de ser conduzida, dependendo do que o professor da escola achasse por bem, assim, métodos e programas indicados não eram cumpridos.

Referente ao Regulamento de 1901 que estava em vigor, Victor Ferreira do Amaral não faz reclamações, pelo contrário, elogia e diz que está de acordo com a atualidade, sem necessidade de modificações. Em contrapartida, alega que o que vinha interferindo em seu cumprimento era a falta de recursos das escolas. Em seu relato, o Diretor informa que gradativamente o mobiliário escolar era melhorado por meio da troca de móveis antigos por bancos-carteiras, mas que por outro lado, a maioria das escolas públicas carecia de material didático e que a falta era quase absoluta, afirmando faltar "os mais rudimentares apparelhos para o ensino pratico de geographia, arithmética etc.” (PARANÁ, 1903, p. 11).

Victor Ferreira do Amaral cita ainda os livros que foram adotados pela Congregação da Escola Normal. Além daqueles citados no Relatório de 1901, há livros de Sebastião Paraná (Geografia), Rocha Pombo (História), Olavo Freire (Geometria), José de Alencar (Literatura) e para a Aritmética os livros de Antônio Trajano: Arithmética Elementar e Arithmética Progressiva.

Já no Relatório de Governo de 1904, tanto o Secretário de Estado Bento José Lamenha Lins e o Diretor da Instrução Pública Reinaldo Machado afirmam que a instrução popular, mesmo nas cidades, é deficiente. Apontam que o Regulamento em vigor se apresenta como obsoleto e falho, estando totalmente em desacordo com os progressos do Estado e com os 
novos conhecimentos da pedagogia. Mas, além destas questões, outro fator que contribuía para a deficiência na instrução pública era o despreparo dos professores. Reinaldo Machado afirmava que para reformar a Instrução era necessário reformar o professorado, pois "sem bons professores e bons methodos não é possivel melhorar o ensino publico" (PARANÁ, 1904, p. 48).

Em se tratando da formação de professores, Machado afirma que a Escola Normal estava deixando a desejar com seus programas e métodos. Segundo ele, o ensino deveria ser mais intuitivo, sem exageros que apenas sobrecarregavam a inteligência e não tinham utilidade prática para a profissão.

No que se refere ao ensino primário, eis o apelo do Diretor da Instrução Pública ao Secretário:

Faz-se mister applicar os melhores methodos, organisando programmas de classes e gráos com todas as minucias possiveis, de modo a que os professores não invoquem ignorancia; alem de que convem uniformisar os livros de leitura adoptando de accordo com o adiantamento das classes uma determinada serie, como ja as ha em língua vernacula. (PARANÁ, 1904, p. 50)

A partir dos Relatórios de Governo observa-se no Paraná uma educação precária que carecia de materiais e, sobretudo, de uma legislação que uniformizasse os programas, métodos de ensino e livros didáticos. Porém, neste contexto, como se efetivou o ensino de Aritmética nas escolas primárias?

\section{O ensino de Aritmética segundo os professores primários}

É possível responder a pergunta anterior mediante um achado muito importante na revista paranaense, intitulada "A Escola - Revista do Gremio dos Professores Publicos"14. Refere-se a relatórios que os professores da capital escreveram a fim de comunicar ao Inspetor Escolar como haviam desenvolvido o trabalho pedagógico no ano anterior. Infelizmente, os relatórios foram publicados em um período curto de tempo, resumindo-se em três, todos referentes ao ano letivo de 1905. A presença dos relatórios na revista "A Escola"

\footnotetext{
${ }^{14}$ O primeiro número da revista foi publicado em fevereiro de 1906. Seus diretores eram Sebastião Paraná e Dário Vellozo e a revista tinha publicação mensal. Sebastião Paraná afirma na primeira edição que a revista vinha para preencher uma lacuna e lutar em prol do progresso da instrução pública e do professorado, "destinada a despertar os animos, a discutir e vulgarizar os bons ensinamentos da sociologia” (PARANÁ, 1906, p. 2).
} 
justifica-se pelo fato de que Sebastião Paraná, um dos editores da revista, era também o Inspetor Escolar da Capital.

O primeiro relatório, publicado na revista "A Escola", foi da professora Julia Wanderley Petrich, que ministrava aulas na Escola Tiradentes em Curitiba. Quanto à organização da classe, a professora relatou que adotara o modo de ensino simultâneo, porém, que dividiu a turma em duas classes, e as classes em seções, com o critério de separá-las entre as mais adiantadas e atrasadas. Referente ao método de ensino, a professora lembrou que a Psicologia mantinha estreitas relações com a Pedagogia, e por isso o professor deve se atentar para o desenvolvimento das potencialidades, sabendo que o método deve adequar-se ao nível de cada aluno:

Aplicando umas vezes o methodoinductivo ou analytico e outras o deductivo ou synthetico, procuro sempre tornar intuitivas e claras as explicações dadas, para que as alumnas possam assim comprehender, assimilar e reter a lição ministrada (PETRIC, 1906, p. 23)

Neste sentido, a professora Julia Wanderley relatou que com as alunas mais atrasadas utilizou o método intuitivo e que isto tinha trazido grandes vantagens à aprendizagem.

A licção partindo das partes para o todo, do simples para o composto, deve basear-se em princípios conhecidos e concretos, cumprindo abandonar por completo todo systema fundado em princípios abstractos. (PETRICH, 1906, p. 23)

A professora se opôs ao ensino ministrado exclusivamente pela memória, defendendo que todas as faculdades da inteligência devem ser exercitadas. Citando a frase de Montaigne afirmou que "saber de cór não é saber" (p. 24) e é por isso que afirma ter procurado ministrar uma sólida instrução, aproximando a vida escolar da vida real.

Neste relatório consta ainda que foram utilizados os livros indicados pela Congregação, inclusive o livro didático “Arithmetica Progressiva”, de Antônio Trajano.

As informações contidas no relatório da professora Julia Wanderley são mais gerais, porém, permite-nos averiguar pelas suas palavras que o ensino ministrado em Aritmética partiu do simples para o complexo, do concreto ao abstrato, buscando sempre fazer relações com o cotidiano dos alunos. Isto também pode ser confirmado quando a professora menciona ter adotado o livro "Arithmetica Progressiva" de Antônio Trajano. 
$\mathrm{Na}$ análise deste livro ${ }^{15}$, observa-se que o conteúdo é organizado de modo gradual, minimamente explicado, dando bastante ênfase para o significado das palavras. Ao se referir aos números, o autor afirma que eles se dividem em pares e ímpares, abstratos e concretos, primos e múltiplos, simples e compostos, decimais e complexos. Os números abstratos são números que não estão "unidos a nome algum" (TRAJANO, 1948, p. 8), já os concretos "são os que estão unidos ao nome dos objetos, como 5 livros" (idem, p.8). A partir do conteúdo das quatro operações o autor insere diversos problemas, com situações variadas.

Na revista “A Escola”, n 2, de março de 1906, é publicado o Relatório apresentado ao Diretor Geral da Instrução Pública pela professora Josephina Carmen Rocha que ministrava aulas na Escola Carvalho em Curitiba. Nesse Relatório, a professora afirmou que o seu ensino é intuitivo e ministrado simultaneamente aos alunos. Relatou que buscou torná-lo fácil e atraente para que os alunos pudessem sentir prazer ao entrar na escola, afirmando que o professor deve dar explicações simples, "mas com a maior somma possivel de conhecimentos úteis" (ROCHA, 1906, p. 44). A professora relata:

\begin{abstract}
Assim é que tendo procurado desenvolver o gosto e a dedicação ao estudo, tornando-o pratico, fazendo com que os alumnos depois de uma explicação de grammatica, por exemplo, applique-a, já fazendo analyse das lições, já escrevendo cartas e fazendo pequenas descripções de objectos do seu conhecimento; o mesmo faço com relação á todas as outras matérias que fazem parte do programma de ensino, partindo sempre do simples para o composto, do concreto para o abstrato, do estudo de cada uma das partes para o estudo de um todo. (ROCHA, 1996, p. 44-45)
\end{abstract}

Verificamos pelas palavras da professora, que tornar o ensino prático é aplicar o conhecimento em alguma situação, que no caso de seu exemplo, se trata dos exercícios. A professora ainda traz a informação de que adotou os livros recomendados, exceto o livro Iracema.

O ultimo relatório foi publicado na revista "A Escola" de 1906, n 4. No discurso do professor Lourenço A. de Souza, percebe-se a carência que sofria a escola de materiais, como por exemplo, mapas e sólidos geométricos, que segundo o professor eram utensílios que concretizavam as explicações, tornando o ensino intuitivo, interessante e atraente nas diversas matérias. O professor também faz menção ao livro de Aritmética de Antônio Trajano:

\footnotetext{
${ }^{15}$ O livro "Arithmetica Progressiva" de Antonio Trajano que tivemos acesso se refere à $78^{\circ}$ edição, do ano de 1948. Encontra-se disponível no Repositório Digital, organizado pelo GHEMAT (Grupo de Pesquisa de História da Educação Matemática no Brasil), e disponibilizado na UFSC (Universidade Federal de Santa Catarina), no endereço eletrônico: https://repositorio.ufsc.br/handle/123456789/1769.
} 
A Arithmetica Elementar do Dr. A. Trajano é um excellente livro (o melhor que conheço, desse gênero, para escolas primárias) e produz sempre bons resultados, porquanto nelle a exposiçao dessa importante matéria é feita pelo methodo pedagógico por excellencia — o intuitivo. (SOUZA, Revista A Escola, 1906, No 4, p. 81-82)

Este livro teve sua primeira publicação em 1879 e tinha como título "Arithmetica

Elementar Illustrada: para uso dos alumnos adiantados das escolas primarias". Conforme esclarece Oliveira (2013), este livro destinava-se às classes mais adiantadas da escola primária e continha todos os conteúdos de Aritmética que o professor deveria trabalhar.

$\mathrm{Na}$ análise da $68^{\circ}$ edição do livro ${ }^{16}$, verifica-se que a linguagem adotada era bastante objetiva e os conteúdos organizados de modo gradual. Cada elemento dos conteúdos aritméticos era trabalhado de modo minucioso, indo do simples ao complexo, acompanhado de exemplos, ilustrações e problemas. Ao término de cada conteúdo constam repetitivos exercícios de aplicação e também problemas referentes ao que havia sido estudado.

O concreto pode ser evidenciado tanto pelas ilustrações que facilitavam a visualização daquilo que o texto estava tratando e também pelos problemas que traziam questões do cotidiano para a sala de aula. Além do mais, os chamados "números concretos" também estavam presentes nesta obra de Antônio Trajano.

\section{Considerações finais}

Nos relatos dos professores foi possível perceber que o ensino de Aritmética na escola primária paranaense, no início do século $\mathrm{XX}$, concretizou-se pelo método intuitivo, desta forma, mesmo sem haver Programas de Ensino oficiais, o conteúdo era organizado de modo gradual, partindo do simples para o composto.

Os professores, que apresentaram seus relatórios ao Inspetor Escolar ao final do ano de 1905, demonstram a preocupação em tornar o ensino simples, de modo a atrair a atenção dos alunos e fazer da aprendizagem um momento prazeroso. O professor Lourenço Souza ao reclamar da falta de materiais para as aulas de Aritmética demonstra que o recurso didático tinha uma função importante no ensino, segundo ele, concretizava as explicações do professor. Além disso, outro fator presente nas falas dos professores é a preocupação em fazer

\footnotetext{
${ }^{16} \mathrm{Na} 68^{\circ}$ edição do livro "Arithmetica Elementar Illustrada: para uso dos alumnos adiantados das escolas primarias" de Antonio Trajano, não consta o ano de publicação, porém, tudo indica ser posterior a 1907. O livro encontra-se disponível no Repositório da UFSC, no endereço eletrônico: https://repositorio.ufsc.br/handle/123456789/1769.
} 


\section{REVISTA REAMEC \\ Revista da Rede Amazônica de Educação \\ em Ciências e Matemática}

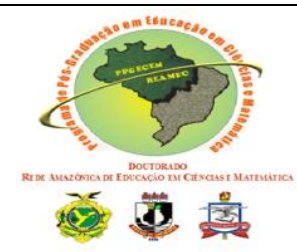

com que os conteúdos tivessem relação com a realidade dos alunos e, assim, lhes fossem propiciados conhecimentos úteis à vida.

A confirmação de que os professores utilizavam os livros recomendados pela Congregação da Escola Normal, em especial os livros "Arithmetica Elementar" e Página | 45 "Arithmetica Progressiva" de Antônio Trajano, corrobora tais constatações, uma vez que os referidos livros são orientados na perspectiva do método intuitivo, e por isso prezam pela organização gradual dos conteúdos, pela presença do concreto no ensino e pela relação Aritmética e realidade, aspectos que dão sentido à dimensão "prática" dispensada ao ensino da Aritmética por escolas primárias do Paraná, no início do século XX.

\section{REFERÊNCIAS}

BENCOSTTA, Marcus Levy Albino. Grupos escolares no Brasil: um novo modelo de Escola Primária. In: BASTOS, Maria Helena Camara; STEPHANOU, Maria (Org.). Histórias e memórias da educação no Brasil: século XX. V. 3.Petrópolis, RJ: Vozes, 2005. p. 68-76.

CHARTIER, Roger. A História Cultural entre práticas e representações. Tradução de Maria Manuela Galhardo. Rio de Janeiro: Bertrand Brasil, 1990, 244 p.

JULIA, Dominique. A cultura escolar como objeto histórico. Campinas, SP. SBHE/Editora Autores Associados. Revista Brasileira de História da Educação. n. 1, Jan/jun., 2001, p. 9-43.

OLIVEIRA, Marcus Aldenisson de. Antônio Bandeira Trajano e o método intuitivo para o ensino de Arithmetica (1879-1954). 2013. 142 f. Dissertação (Mestrado em Educação) Universidade Tiradentes: Sergipe, 2013.

PARANÁ. Decreto n ${ }^{\circ}$ 93, de 11 de março de 1901. Regulamento da Instrução Pública do Estado do Paraná. Leis, Decretos e Regulamentos do Estado do Paraná, 1901. Curitiba, PR: Typ. da Penitenciária do Ahú, s.d.

PARANÁ. Relatório apresentado ao Governador do Estado do Paraná pelo Dr, Octavio Ferreira do Amaral e Silva. Curitiba: Tip. da Penitenciária Geral do Estado, 1901, 82 p.

Relatório apresentado ao Secretário do Interior, Justição e Instrucção Pública pelo Dr, Victor Ferreira do Amaral e Silva. Curitiba: Tip. da Penitenciária Geral do Estado, 1903, $64 \mathrm{p}$.

. Relatório da Secretaria D’Estado dos Negócios do Interior, Justiça e instrução pública. Curitiba: Tip. da Penitenciária Geral do Estado, 1904, 173p.

PARANÁ, Sebastião. A escola. A Escola - Revista do Gremio dos professores públicos do Estado do Paraná. Curitiba, ano I, nº 1, p. 1-2, fevereiro, 1906.

PETRICH, Julia Wanderley. Relatórios. A Escola - Revista do Gremio dos professores públicos do Estado do Paraná. Curitiba, ano I, nº 1, p. 17-25, fevereiro, 1906.

PILOTTO, Erasmo. A educação no Paraná: Síntese sobre o ensino público elementar e médio. Rio de Janeiro: INEP, 1954, 130 p. 


\section{REVISTA REAMEC \\ Revista da Rede Amazônica de Educação em Ciências e Matemática}

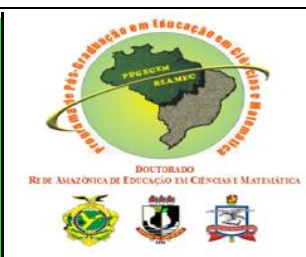

ROCHA, Josephina Carmen. Relatório. A Escola - Revista do Gremio dos professores públicos do Estado do Paraná. Curitiba, ano I, nº 2, p. 43-46, março, 1906.

SOUZA, Lourenço A. Relatório. A Escola - Revista do Gremio dos professores públicos do Estado do Paraná. Curitiba, ano I, nº 4, p. 78-83, maio, 1906.

SOUZA, Rosa Fátima de. Templos de civilização: A implantação da escola primária graduada no Estado de São Paulo (1890-1910). São Paulo: Fundação Editora UNESP, 1998, 284 p.

TRAJANO, Antonio. Arithmetica Elementar Illustrada: para uso dos alumnos adiantados das escolas primarias. $68^{\circ}$ Ed. Rio de Janeiro: Tipografia Martins de Araújo, s. d., 135 p.

Arithmetica Progressiva. 78 Ed. Rio de Janeiro: Livraria Francisco Alves, 1948, 240 p. 